\title{
ANALISIS SIFAT FISIK DAN MEKANIS BETON PASCA BAKAR
}

\author{
Sari Utama Dewi ${ }^{1}$, Fery Hendi Jaya ${ }^{2}$, M. Ade Khairil ${ }^{3}$ \\ Prodi Teknik Sipil Universitas Muhammadiyah Metro ${ }^{1}$,Prodi Teknik sipil Universitas Sang \\ Bumi Ruwa Jurai ${ }^{2,3}$ \\ E-mail : saridewi.dewi1981@gmail.com ${ }^{1}$, feryhjaya@gmail.com² \\ ad3dugem@gmail.com ${ }^{3}$
}

\begin{abstract}
ABSTRAK
Tujuan dari penelitian ini adalah untuk mengetahui sifat fisik dan mekanik beton pasca bakar untuk beton K-225, K250 dan K-300 dengan waktu pembakaran selama 3 jam, 6 jam dan 9 jam dan temperatur $200^{\circ} \mathrm{C}$. Dari hasil penelitian pada waktu pembakaran 3 jam didapat kuat tekan menurun sebesar 19,236 \%, 7,96 \% pada K-225 dan K-250 dari kekuatan awal beton, sedangkan pada K-300 beton semakin naik dan kuat sebesar 13,454 $\%$ dari kekuatan awal beton. Pada waktu pembakaran 6 jam kuat tekan beton pada K-225 dan K-250 menurun sebesar 24,076 \% dan 17,641 \% dari kekuatan awal beton. Sedangkan pada waktu pembakaran 9 jam, kuat tekan beton pada K-300 mengalami kenaikan sebesar $2,255 \%$. kuat tekan terbesar berada pada K-250 sebesar $202,490 \mathrm{~kg} / \mathrm{cm}^{2}$. Artinya beton semakin lemah dan kuat tekan beton berturut-turut menurun sebesar 18,939\%, 19,899\% dan 17,287 \% dari kekuatan awal beton. Untuk porositas beton dengan waktu pembakaran 3 jam dapat dilihat bahwa semakin meningkat mutu beton, porositas semakin bertambah. Porositas beton dengan waktu pembakaran 6 jam dapat diliat bahwa semakin meningkat mutu beton, porositas semakin bertambah tetapi pada mutu beton K-300 nilai porositas menurun. Sedangkan porositas beton dengan waktu pembakaran dapat diliat bahwa semakin meningkat mutu beton, porositas semakin bertambah tetapi pada mutu beton $\mathrm{K}$ 300 nilai porositas menurun.
\end{abstract}

Kata Kunci : Kebakaran, Kuat Tekan, Porositas.

\section{PENDAHULUAN}

Beton merupakan bahan bangunan tahan api yang relatif baik karena merupakan bahan dengan penghantar panas yang tidak besar sehingga dapat menahan struktur beton dari penyebaran panas. Beton tidak dapat menyebabkan kebakaran ketika terbakar, tetapi dapat menyerap panas karena suhunya terlalu tinggi dan mengubah struktur beton. Perubahan / kerusakan yang disebabkan kebakaran dipengaruhi oleh suhu dan waktu pembakaran, sifat kombinasi beton, dan sifat dari pembebanan.

Kebakaran yang terjadi di suatu bangunan dapat menyebabkan kerugian besar yaitu kerusakan pada bangunan. Kerusakan pada bangunan yang terjadi karena adanya perubahan kenaikan suhu saat terjadi kebakaran, pengaruh komponen struktur bangunan karena adanya perubahan fasa fisik dan fasa kimia secara kompleks yang disebabkan oleh siklus pendingin dan siklus pemanasan. Sehingga beton akan menjadi rapuh karena disebabkan oleh adanya pengaruh kualitas serta kekuatan pada struktur beton. Dalam penanganan bangunan setelah kebakaran terjadi, terdapat permasalahan utama yaitu ketika mengevaluasi residual strenght setelah kebakaran dan mengambil tindakan korektif secara efisien agar dapat 
mengembalikannya ke keadaan seperti awal, sehingga bangunan dapat digunakan kembali. Hingga saat ini, meskipun komponen sebuah bangunan yang terbakar masih bisa kuat dan digunakan, bangunan tersebut segera dimusnahkan (demolition measures).

\section{TINJAUAN PUSTAKA}

Beton adalah bahan komposit yang merupakan campuran antara pasir, batu pecah, krikil, hingga agregat lainnya dengan air dan pasta semen yang akan membentuk batu. Dengan bahan tambahan yang diberikan untuk membuat beton memiliki sifat khusus, seperti memilikki kemampuan kerja, waktu, dan daya tahan yang baik. Agregat memiliki fungsi yaitu sebagai pemberi kekuatan, semen memiliki sifat kekuatan yang lebih kecil dari pengikat, dan air (pencampur) memiliki fungsi sebagai sarana pencampuran untuk melihat sifat homogen sebuah komposisi komponen bangunan.

Beton memiliki berbagai keunggulan yang sehingga banyak yang menggunakan. Terdapat beberapa sifat unggul pada beton, antara lain seperti:

a. Menggunakan bahan dasar seperti air, semen, dan agregat.

b. Ketahanan tinggi terhadap kompresi.

c. Penggunaan yang mudah (serbaguna).

d. Beton memiliki sifat adaptabilitas monolitik, dimana tidak membutuhkan sambungan seperti baja.

e. Perawatan minimum, dimana beton secara umum dapat bertahan cukup lama, tahan terhadap oksidasi, tahan terhadap korosi (kebakaran), dan dapat tidak perlu dicat.

\section{Agregat}

Beberapa faktor penting dalam agregat, yaitu seperti:

1. Kuat.

2. Tahan terhadap cuaca.

3. Tahan lama.

4. Menghindari terjadinya reaksi kimia antara material dan semen.

5. Permukaan bebas dari kotoran.

\section{Kekuatan Agregat}

Kekuatan beton lebih rendah dibandingkan kekuatan agregat. Dikarenakan jika kuat tekan beton lebih rendah daripada kuat tekan agregat maka agregat tersebut dapat dipergunakan untuk bahan adukan beton. Terdapat kasus tertentu ketika terjadi konsentrasi tegangan lokal beton mutu tinggi cenderung memiliki kekuatan seluruh beton dengan tegangan lebih tinggi.

\section{Faktor Yang Mempengaruhi Kekuatan Agregat}

Agregat dapat bersifat kurang kuat jika:

1. Terdiri dari partikel yang kuat atau terhindar dari bahan yang lemah tetapi lemah dalam pengikatan.

2. Beban kejut ditentukkan dengan keuletan yang dipengaruhi oleh porositas yang besar.

\section{Semen}

Semen merupakan bahan material untuk mengikat agregat untuk memiliki massa yang padat dan kekuatan yang kuat karena mempunyai sifat adhesif dan kohesif. Selain itu semen juga hasil industri dimana dari paduan antara bahan baku utamanya, dimana seperti kapur / batu gamping dan tanah liat / lempung. Kapur / batu gamping merupakan bahan alam yang memiliki kandungan senyawa Calcium Oksida $(\mathrm{CaO})$, sedangkan tanah liat / lempung merupakan bahan alam yang memiliki kandungan senyawa Silica Oksida $\left(\mathrm{SiO}_{2}\right)$, Aluminium Oksida (Al$\left.{ }_{2} \mathrm{O}_{3}\right)$, Magnesium Oksida (MgO), dan Besi Oksida $\left(\mathrm{Fe}_{2} \mathrm{O}_{3}\right)$ atau bahan pengganti lainnya dengan hasil akhir seperti padatan dengan bentuk bubuk (bulk). Bahan baku kemudian dibakar sampai meleleh agar dihasilkannya semen, sebagian untuk membentuk clinkernya. Tahap selanjutnya bahan baku dihancurkan kemudian ditambah dengan 
gips (gypsum) dengan jumlah sesuai standar.

\section{Faktor Air Semen (FAS)}

Berlebihnya air pada beton akan mengakibatkan ruang pada beton yang menimbulkan pori saat beton mengeras. Ketika mutu beton rendah maka FAS akan semakin tinggi. Namun, nilai FAS yang rendah bukan berarti mutu beton semakin tinggi. Rendahnya mutu beton dan sulitnya pelaksanaan pemadatan beton dapat diakibatkan karena nilai FAS yang rendah, dimana nilai FAS yang baik sekitar $0,4-0,65$. Ketebalan lapisan pemisah antara partikel pada beton dan kehalusan butir suatu semen dapat dipengaruhi oleh nilai FAS.

Air

Beberapa faktor yang dapat mempengaruhi kebutuhan air yaitu:

1. Memiliki ukuran agregat yang maksimun, dimana kebutuhan air akan menurun jika diameter mengalami kenaikan sehingga penggunaan mortar menurun.

2. Kebutuhan air menurun yang akan menunjukkan bentuk butir bulat.

3. Terdapatnya gradasi pada agregat, dimana kondisi gradasi yang baik terjadi saat penggunaan kebutuhan air yang menurun.

4. Kotoran dalam agregat.

5. Perbandingan perubahan kebutuhan air pada agregat halus.

\section{Kebakaran Pada Bangunan}

Fase secara fisik ataupun kimia yang terjadi secara kompleks akan menyebabkan terjadinya siklus pemanasan dan pendinginan pada struktur kolom, balok, lantai, dinding akan terjadi ketika terjadinya kebakaran pada bangunan. Kebakaran ini mengakibatkan perubahan mikrostruktur beton sehingga kekuatan struktur material beton mengalami penurunan.

\section{Ketahanan Beton terhadap Kebakaran}

Beton akan mengalami degradasi saat dipanaskan dengan suhu di atas $800^{\circ} \mathrm{C}$ yaitu keadaan ketika kekuatan mengalami pengurangan yang signifikan dan memungkinkan akan recovery setelah dilakukan pendinginan beton. Menurut Jokrodimuljo 2000, pada dasarnya beton tidak dapat menahan panas hingga di atas $250^{\circ} \mathrm{C}$. Jenis material yang digunakan mempengaruhi kekuatan beton.

Kuat tekan material beton dapat berkurang dikarenakan lamanya waktu pembakaran dan tingkat keparahan temperatur yang tinggi. Perbedaan sifat panas / termal pada semen dan agregat akan mengakibatkan tegangan geser dalam (Internal Shear Stress).

\section{Pengaruh Temperatur Tinggi Terhadap Beton}

Perubahan sifat material beton disebabkan karena temperatur yang meningkat saat terjadinya kebakaran. Ruangan suatu gedung yang terbakar bisa mencapai $\pm 1000^{\circ} \mathrm{C}$ dengan lama kebakaran baisanya > 1 jam. Karbonat, beton dengan berbobot ringan, dan silikat merupakan jenis golongan agregat beton yang structural. Dimana agregat karbonat terdiri dari dolomit dan batu kapur yang dimasukkan kedalam satu golongan pada suhu $700^{\circ} \mathrm{C}$ hingga $980^{\circ} \mathrm{C}$ karena akan terjadinya perubahan susunan kimia. Sedangkan agregat silikat terdiri dari batu pasir, kuarsit, dan granit yang enggan terjadi perubahan kimia pada suhu biasa saat terjadinya kebakaran (Norman Ray, 2009).

Perubahan yang terjadi pada beton saat mengalami temperatur tinggi adalah

1. Suhu $100^{\circ} \mathrm{C}$ : akan menguapnya air kapiler.

2. Suhu $200^{\circ} \mathrm{C}$ : akan terjadinya penyusutan pasta yang diakibatkan karena agregat menguap.

3. Suhu $400^{\circ} \mathrm{C}$ : kekuatan beton 
terganggu yang disebabkan oleh pasta semen yang telah terhidrasi terurai kembali.

\section{Identifikasi Kebakaran Terhadap Struktur Beton}

1. Beton mengalami perubahan

Beton mengalami perubahan ketika proses pendingan terjadi. Perubahan warna yang terjadi pada permukaan beton :

- $<300^{0} \mathrm{C}$ : tidak berubah

- $300^{\circ} \mathrm{C}-600^{\circ} \mathrm{C}$ : merah muda

- $600^{\circ} \mathrm{C}-900^{0} \mathrm{C}$ : putih keabuabuan

- $>900^{\circ} \mathrm{C}$ : kekuning-kuningan

- $>1200^{\circ} \mathrm{C}$ : kuning

2. Crazing dan spalling pada beton

Gejala lepasnya permukaan beton dalam beberapa $\mathrm{cm}$ lapisan tipis disebut dengan spalling. Spaling juga diartikan sebagai bagian permukaan beton yang lepas atau terpisah. Sedangkan gejala remuk pada permukaan beton disebut dengan crazing, yang berbentuk seperti kulit telur yang pecah. Spalling terjadi pada $150^{\circ} \mathrm{C}-1110^{\circ} \mathrm{C}$, destructive cracking terjadi pada $220^{\circ} \mathrm{C}-400^{\circ} \mathrm{C}$. Jadi beton mulai kritis pada $300^{\circ} \mathrm{C}-350^{\circ} \mathrm{C}$

3. Cracking atau Retak

Klasifikasi retakan beton yaitu :

- Retak ringan, terjadi saat kebakaran yang biasa disebabkan karena beton mengalami penyusutan.

- Retak berat, terjadi secara kelompok ataupun tunggal.

\section{Porositas Beton}

Porositas merupakan perbandingan antara volume pori-pori dengan volume total beton. Porositas beton ialah gelembung udara yang membentuk pori beton yang tidak dapat keluar dari pasta beton. Ketika gelembung udara tidak bisa keluar dari beton maka minimbulkan keropos pada beton dan beton mengalami penurunan kekuatan. Sehingga proses pemadatan pada beton harus diperhatikan agar tidak terjadinya keropos pada beton.

Penurunan kekuatan dapat dipengaruhi karena adanya peningkatan porositas. Porositas yang memiliki rongga terhadap permukaan luar meskipun pada tengah-tengah rongga tersebut masih padat merupakan bentuk porositas terbuka. Variasi besar porositas suatu material yakni mulai dari $0 \%$ - 90 $\%$ yang bergantung dengan jenis dan aplikasi material. Besar atau nilai porositas dapat dihitung dengan menggunakan persamaan seperti berikut:

$$
p=\frac{m_{b}-m_{k}}{v_{b}} x \frac{1}{\rho_{\text {air }}} x 100 \%
$$

Dimana $\mathrm{p}$ merupakan porositas (\%), $\mathrm{m}_{\mathrm{b}}$ merupakan massa basah sampel setelah direndam $(\mathrm{gram}), \mathrm{m}_{\mathrm{k}}$ merupakan massa kering sampel (gram), dan $\mathrm{v}_{\mathrm{b}}$ merupakan volume benda yang akan diuji $\left(\mathrm{cm}^{3}\right)$, dan $\rho_{\text {air }}$ merupakan massa jenis air $\left(\mathrm{cm}^{3}\right)$.

\section{METODE PENELITIAN}

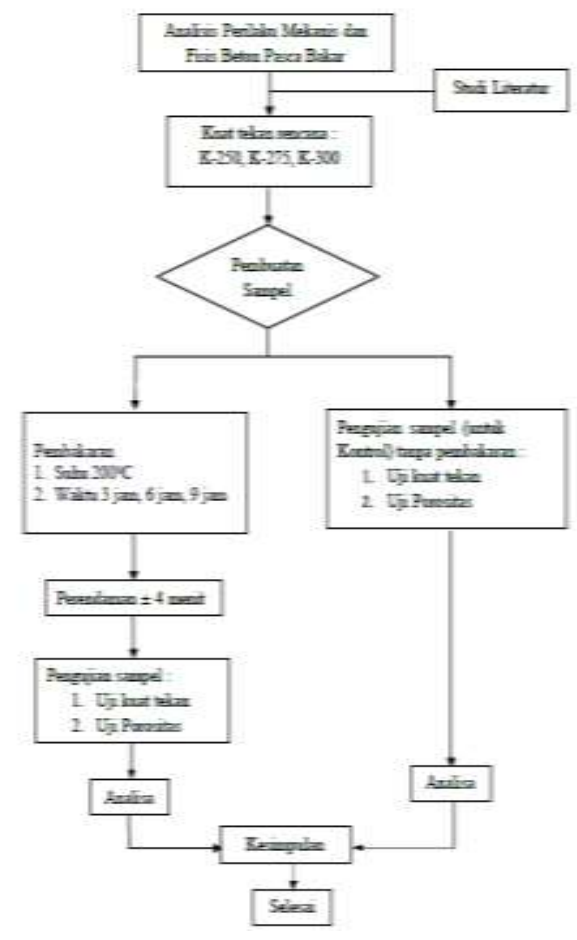

Gambar 1. Diagram Alir Penelitian (Sumber : Hasil Penelitian, 2021) 
HASIL PENELITIAN

Pengujian Kuat Tekan Beton

Tabel 1. Beton Normal Tanpa Pembakaran

\begin{tabular}{|c|c|}
\hline Mutu Beton & $\begin{array}{c}\text { Kuat Tekan Rata- } \\
\text { Rata }\left(\mathbf{k g} / \mathbf{c m}^{\mathbf{2}}\right)\end{array}$ \\
\hline K-225 & 211,630 \\
\hline K-250 & 252,795 \\
\hline K-300 & 241,193 \\
\hline
\end{tabular}

(Hasil Penelitian, 2021)

Tabel 2. Data Kuat Tekan Beton dengan Pembakaran dan Waktu Penahanan 3 Jam

\begin{tabular}{|c|c|}
\hline Mutu Beton & $\begin{array}{c}\text { Kuat Tekan Rata- } \\
\text { Rata }\left(\mathbf{k g} / \mathbf{c m}^{\mathbf{2}}\right)\end{array}$ \\
\hline K-225 & 170,921 \\
\hline K-250 & 232,673 \\
\hline K-300 & 273,642 \\
\hline
\end{tabular}

(Hasil Penelitian, 2021)

Tabel 3. Data Kuat Tekan Beton dengan Pembakaran dan Waktu Penahanan 6 Jam

\begin{tabular}{|c|c|}
\hline Mutu Beton & $\begin{array}{c}\text { Kuat Tekan Rata- } \\
\text { Rata }\left(\mathbf{k g} / \mathbf{c m}^{2}\right)\end{array}$ \\
\hline K-225 & 160,677 \\
\hline K-250 & 208,200 \\
\hline K-300 & 246,631 \\
\hline
\end{tabular}

(Hasil Penelitian, 2021)

Tabel 4. Data Kuat Tekan Beton dengan Pembakaran dan Waktu Penahanan 9 Jam

\begin{tabular}{|c|c|}
\hline Mutu Beton & $\begin{array}{c}\text { Kuat Tekan Rata- } \\
\text { Rata }\left(\mathbf{k g} / \mathbf{c m}^{\mathbf{2}}\right)\end{array}$ \\
\hline K-225 & 171,550 \\
\hline K-250 & 202,490 \\
\hline K-300 & 199,499 \\
\hline
\end{tabular}

(Hasil Penelitian, 2021)

Tabel 5. Mutu Beton dengan Kuat Tekan

\begin{tabular}{|c|c|c|c|}
\hline \multirow{2}{*}{$\begin{array}{l}\text { Mutu } \\
\text { Beton }\end{array}$} & \multicolumn{3}{|c|}{ Waktu Penahanan } \\
\cline { 2 - 4 } K-225 & 170,921 & 232,673 & 273,642 \\
\hline K-250 & 160,677 & 208,200 & 246,631 \\
\hline K-300 & 171,55 & 202,490 & 199,499 \\
\hline
\end{tabular}

(Hasil Penelitian, 2021)
Berdasarkan dari Tabel 5 menunjukkan keseragaman dimana kuat tekan beton naik seiring dengan kenaikan mutu beton. Pada K-250 penurunan sebesar 2,44 \% - 36,44 \%, pada K-300 penurunan sebesar $16,05 \%-28,87 \%$. Sedangkan pada K-225 terjadi penurunan 19,236 \% dengan waktu penahanan 3 jam dan kenaikan sebesar 9,94\% - 29,30\% dengan waktu penahanan 6 jam dan 9 jam.

Tabel 6. Waktu dan Kuat Tekan

\begin{tabular}{|c|c|c|c|}
\hline \multirow{2}{*}{$\begin{array}{c}\text { Waktu } \\
\text { (Jam) }\end{array}$} & \multicolumn{3}{|c|}{ Waktu Penahanan } \\
\cline { 2 - 4 } & K-225 & K-250 & K-300 \\
\hline 3 & 170,921 & 160,677 & 171,550 \\
\hline 6 & 232,673 & 208,200 & 202,490 \\
\hline 9 & 273,642 & 246,631 & 199,499 \\
\hline
\end{tabular}

(Hasil Penelitian, 2021)

Tabel diatas menunjukkan menunjukkan keseragaman bahwa kuat tekan beton akan naik seiring dengan semakin lamanya waktu penahanan (durasi pembakaran) dan persentase kenaikan semakin besar dengan semakin meningkatnya mutu beton.

Dari perbandingan nilai antara kenaikan mutu beton terhadap kuat tekan dengan kenaikan waktu penahanan pada kuat tekan, dapat diambil kesimpulan bahwa kenaikan mutu beton dapat menyebabkan penurunan kuat tekan beton.

\section{Pengujian Porositas Beton}

Tabel 7. Data Porositas Beton dengan Pembakaran dan Waktu Penahanan 3 Jam

\begin{tabular}{|c|c|}
\hline Mutu Beton & Porositas Beton \\
\hline K-225 & 1,007 \\
\hline K-250 & 1,659 \\
\hline K-300 & 2,560 \\
\hline
\end{tabular}

(Hasil Perhitungan, 2021) 
Tabel 8. Data Porositas Beton dengan Pembakaran dan Waktu Penahanan 6 Jam

\begin{tabular}{|c|c|}
\hline Mutu Beton & Porositas Beton \\
\hline K-225 & 1,659 \\
\hline K-250 & 6,163 \\
\hline K-300 & 2,960 \\
\hline
\end{tabular}

(Hasil Perhitungan, 2021)

Tabel 9. Data Porositas Beton dengan Pembakaran dan Waktu Penahanan 9 Jam

\begin{tabular}{|c|c|}
\hline Mutu Beton & Porositas Beton \\
\hline K-225 & 5,333 \\
\hline K-250 & 8,237 \\
\hline K-300 & 10,844 \\
\hline
\end{tabular}

(Hasil Perhitungan, 2021)

Tabel 10. Data Porositas Beton dengan Pembakaran dan Waktu Penahanan

\begin{tabular}{|c|c|c|c|}
\hline \multirow{2}{*}{$\begin{array}{c}\text { Mutu } \\
\text { Beton }\end{array}$} & \multicolumn{3}{|c|}{ Porositas (\%) } \\
\cline { 2 - 4 } & 3 Jam & 6 Jam & 9 Jam \\
\hline K-225 & 1,007 & 1,659 & 5,333 \\
K-250 & 1,659 & 6,163 & 8,237 \\
K-300 & 2,560 & 2,960 & 10,844 \\
\hline
\end{tabular}

(Hasil Perhitungan, 2021)

Tabel 11. Waktu dan Porositas

\begin{tabular}{|c|c|c|c|}
\hline \multirow{2}{*}{ Waktu } & \multicolumn{3}{|c|}{ Porositas (\%) } \\
\cline { 2 - 4 } & K-225 & K-250 & K-300 \\
\hline 3 Jam & 1,007 & 1,659 & 2,560 \\
6 Jam & 1,659 & 6,163 & 2,960 \\
9 Jam & 5,333 & 8,237 & 10,844 \\
\hline
\end{tabular}

(Hasil Perhitungan, 2021)

Dari tabel diatas dapat diambil kesimpulan, semakin meningkat waktu pembakaran pada mutu beton K-225, K250 dan K-300 maka nilai prositas semakin naik artinya kenaikan mutu beton dan waktu pembakaran memberi dampak yang lebih besar terhadap meningkatnya porositas beton, dikarenakan air $\left(\mathrm{H}_{2} \mathrm{O}\right)$ yang berada pada beton akan menguap. Dimana beton yang terbakar akan terjadi penguapan air bebas pada pori-pori kapiler dengan ukuran besar, dan disusul dengan air pada poripori gel dengan ukuran lebih kecil namun terikat dengan gesekan lebih kuat yang akan menyebabkan terjadinya kondisi tersebut. Molekul air yang akan keluar (migrasi) terhalang, maka terjadi gesekan dengan pori-pori beton akibatnya timbul retak-retak mikro, sehingga porositas beton meningkat.

\section{Pengaruh Perubahan Temperatur Terhadap Kuat Tekan}

\section{Regresi Linear}

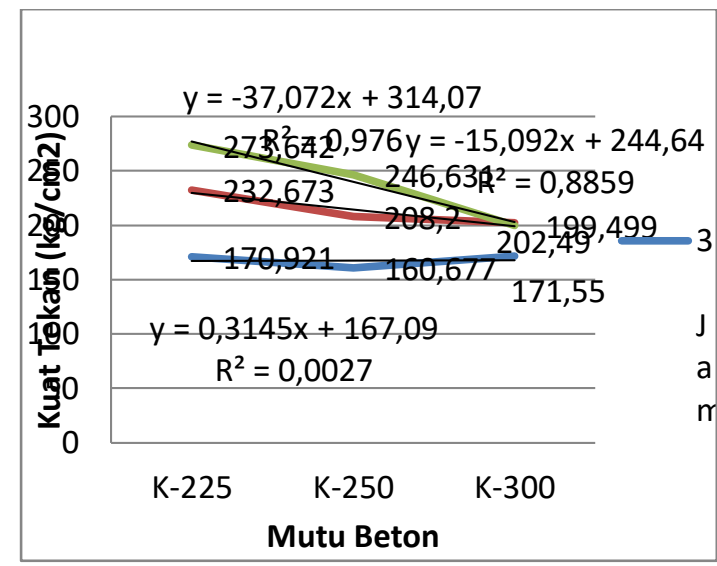

Gambar 2. Regresi Linear Grafik Mutu Beton dengan Kuat Tekan

Dari gambar grafik diatas yang menjadi variabel bebas (x) adalah mutu beton, sedangkan variabel terikat (y) adalah kuat tekan beton. Persamaan regresi yang dihasilkan adalah :

a. Untuk Pembakaran 3 jam : $y=0,3145 x+167,09$ dengan $R^{2}=0,0027$

b. Untuk Pembakaran 6 jam : $y=-15,092 x+244,64$ dengan $R^{2}=0,8859$

c. Untuk Pembakaran 9 jam : $y=-37,072 x+314,07$ dengan $R^{2}=0,976$ 


\section{Regresi Polinomial}

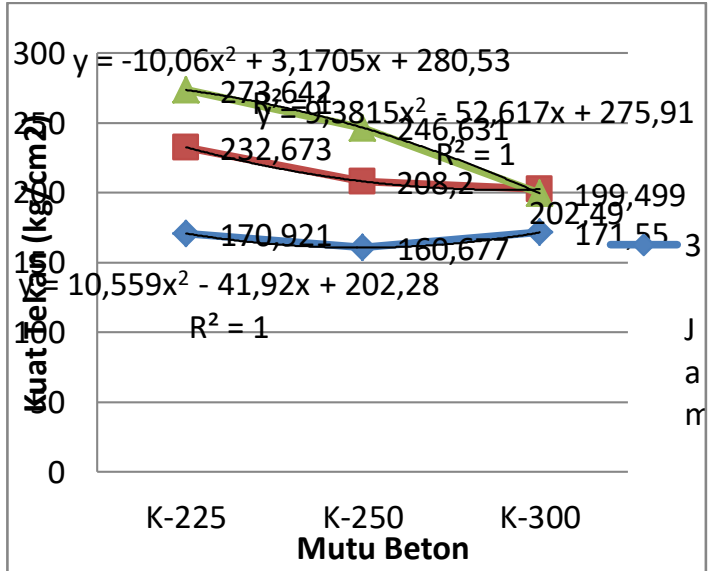

Gambar 3. Grafik Regresi Polinomial Grafik Mutu Beton dengan Kuat Tekan

Dari gambar grafik diatas yang menjadi variabel bebas (x) adalah mutu beton, sedangkan variabel terikat (y) adalah kuat tekan beton. Persamaan regresi yang dihasilkan adalah :

Untuk Pembakaran 3 jam : $y=$ $10,559 x^{2}-41,92 x+202,28$ dengan $R^{2}=1$

Untuk Pembakaran 6 jam : $y=$ $9,3815 x^{2}-52,617 x+275,91$ dengan $R^{2}=1$

Untuk Pembakaran 9 jam : $y=$ $-10,06 x^{2}+3,1705 x+208,53$ dengan $R^{2}=1$

\section{Pengaruh Perubahan Waktu Pembakaran Terhadap Kuat Tekan}

\section{Regresi Linear}

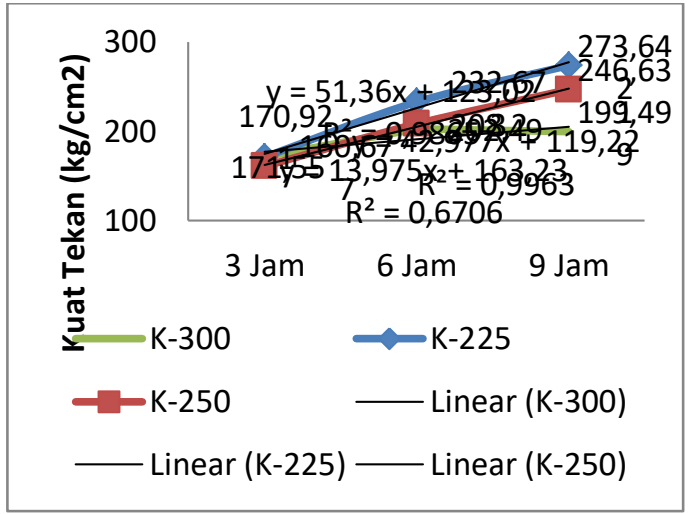

Gambar 4. Regresi Linear Grafik Waktu dan Kuat Tekan
Berdasarkan gambar grafik diatas, variabel bebas ( $\mathrm{x})$ merupakan waktu pemakaran, dan variabel terikat (y) merupakan kuat tekan beton. Persamaan regresi yang dihasilkan adalah :

Untuk Pembakaran 3 jam : $y=$ $13,975 x+163,23$ dengan $R^{2}=0,6706$ Untuk Pembakaran 6 jam : $y=$ $42,977 x+119,22$ dengan $R^{2}=0,9963$ Untuk Pembakaran 9 jam : $y=$ $51,36 x+123,02$ dengan $R^{2}=0,9865$

\section{Regresi Polinomial}

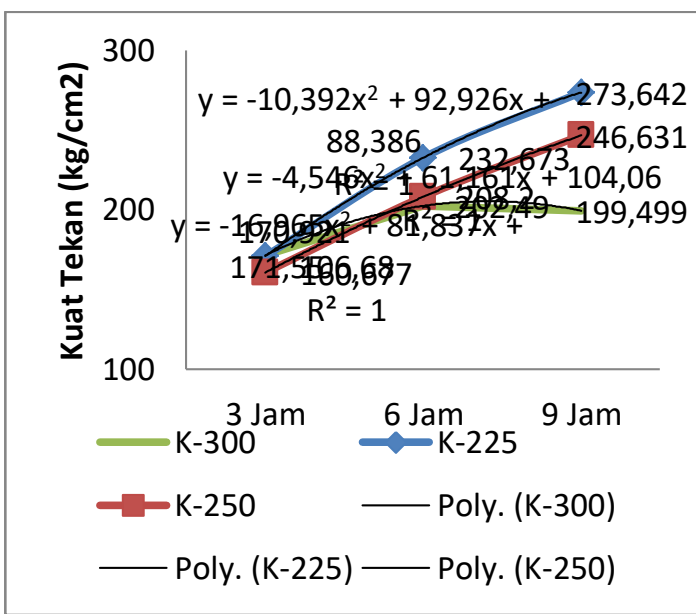

Gambar 5. Regresi Polinomial Grafik Waktu dan Kuat Tekan

Berdasarkan dari grafik diatas variabel bebas (x) merupakan waktu pembakaran, dan variabel terikat (y) merupakan kuat tekan beton. Persamaan regresi yang dihasilkan adalah :

Untuk Pembakaran 3 jam : $y=$ $-16,965 x^{2}+81,837 x+106,68$ dengan $R^{2}=1$

Untuk Pembakaran 6 jam : $y=$ $-4,546 x^{2}+61,161 x+104,06$ dengan $R^{2}=1$

Untuk Pembakaran 9 jam : $y=$ $-10,392 x^{2}+92,926 x+88,836$ dengan $R^{2}=1$

Perkiraan kuat tekan beton setelah terjadi kebakaran pada perencanaan struktur beton dapat dihitung dengan menggunakan beberapa persamaan regresi tersebut. Kita dapat 
memperkirakan mutu beton tertinggi yang terjadi dari hasil survei lapangan dan laboratorium. Dimana nilai kuat tekan sisa didapatkan dari substitusi antara mutu beton dengan persamaan regresi. Nilai tersebut kemudian digunakan untuk menghitung kekuatan tampang elemen struktur beton dan bisa digunakan sebagai dasar layak tidakkah struktur tersebut digunakan kembali. Sehingga dengan demikian dapat direncanakan metode perbaikan yang tepat dalam mengatasi masalah tersebut.

\section{KESIMPULAN}

Kesimpulan yang diperoleh dalam penelitian ini adalah sebagai berikut:

1. Beton mengalami penurunan kekuatan dengan meningkatnya suhu, dimana mutu beton sangat penting dari sifat mekanik suatu beton.

2. Waktu pembakaran akan mempengaruhi kuat tekan suatu beton, dimana beton yang lemah terjadi akibat waktu pembakaran yang lama.

3. Semakin tinggi mutu beton, semakin tinggi porositas beton tersebut. Kuat tekan beton berbanding terbalik porositasnya. Semakin rendah porositas beton maka semakin tinggi nilai kuat tekan beton tersebut, karena sebagian besar air $(\mathrm{H} 2 \mathrm{O})$ yang terkandung dalam beton menguap. Porositas yang meningkat menyebabkan kuat tekan beton menurun dan strukutr beton menjadi rusak.

4. Semakin lama durasi pembakaran beton, semakin tinggi porositas beton.

5. Menghitung kekuatan sisa struktur beton dan sebagai acuan untuk merencanakan metode perbaikan yang sesuai didapatkan berdasarkan persamaan regresi.

\section{DAFTAR PUSTAKA}

Ahmad, I.A., Taufieq, N.A.S., dll. 2009. Analisis Pengaruh Temperatur Terhadap Kuat Tekan Beton. Jurnal Teknik Sipil Vol. 16 No. 2.

Febrina, F. 2010. Pengaruh Suhu dan Waktu Pembakaran Pada Struktur Beton Terhadap Kuat Tekan Beton. Departemen Fisika Universitas Sumatera Utara. Medan.

Kurniawan, S. (2016). Analisa Perawatan Beton Cetak Menggunakan Uap. TAPAK (Teknologi Aplikasi Konstruksi): Jurnal Program Studi Teknik Sipil, 5(2).

Mulyono, T. 2004. Teknologi Beton. Penerbit Andi. Yogyakarta.

Neville dan Brooks. 1987. Bahan dan Praktek Beton. Penerbit Erlangga. Jakarta.

Sari Utama Dewi, Rudi Purnomo. 2016. Pengaruh Tambahan Limbah Plastik HDPE (High Density Polyethylene) Terhadap Kuat Tekan Beton Pada Mutu K-125. Jurnal Tapak Universitas Muhammadiyah Metro Vol. 6 No. 1.

Sutapa, Dede, A.A. 2011. Porositas Kuat Tekan dan Kuat Tarik Belah Beton dengan Agregat Kasar Batu Pecah Pasca Dibakar. Jurnal Ilmiah Teknik Sipil Vol. 15 No. 1. Tjokrodimuljo, K. 1996. Teknologi Beton. Penerbit Nafigiri. Yogyakarta. 